\title{
Planning, Optimisation and Evaluation of Small PtGtP Systems under current German market conditions
}

This paper was downloaded from TechRxiv (https://www.techrxiv.org).

\section{LICENSE}

CC BY 4.0

SUBMISSION DATE / POSTED DATE

$30-04-2021 / 30-04-2021$

\section{CITATION}

Buchholz, Alexander August lonnis; Schmeling, Lucas; Heineke, Hilmer (2021): Planning, Optimisation and Evaluation of Small PtGtP Systems under current German market conditions. TechRxiv. Preprint. https://doi.org/10.36227/techrxiv.14518647.v1

$\mathrm{DOI}$

10.36227/techrxiv.14518647.v1 


\title{
Planning, Optimisation and Evaluation of Small PtGtP Systems under current German market conditions
}

\author{
Alexander August Ionnis Buchholz*, Lucas Schmeling ${ }^{\dagger \ddagger}$, Hilmer Heineke* \\ *New Power Pack GmbH, Kopernikusstraße 23, 49377 Vechta, Germany \\ ${ }^{\dagger}$ KEHAG Energiehandel GmbH, Im Technologiepark 4, 26129 Oldenburg, Germany \\ ${ }^{\ddagger}$ German Aerospace Center (DLR), Institute of Networked Energy Systems, \\ Carl-von-Ossietzky-Straße 15, 26129 Oldenburg, Germany \\ Email: †lucas.schmeling@ kehag.de, ${ }^{\ddagger} l u c a s . s c h m e l i n g @$ dlr.de
}

\begin{abstract}
In the course of the energy transition, distributed, hybrid energy supply concepts, such as the combination of Photovoltaic (PV) and a battery storage system, are increasingly being used for economic and ecological reasons. However, electricity generation is often weather-dependent and the storage capacity of battery storage systems is limited. Nowadays, a new component is emerging for distributed energy supply: the Powerto-Gas-to-Power (PtGtP) technology. It can be used for the longterm storage of electricity in the form of hydrogen. As this is still a fairly new application, methods for planning, design and operation are still missing. For this purpose, a tool is developed to simulate various sizes and combinations of technical systems on the basis of the oemof framework. The evaluation is based on a multi-criteria approach in the form of a Pareto front and is intended to provide the best possible support for the decisionmaking process. In order to gain further insights from this energy supply concept, a sensitivity analysis is then carried out, where key parameters are identified and their effects on the results are described. The methodology is demonstrated using a German dairy as an example and shows that PtGtP is currently not yet profitable but promising.
\end{abstract}

\section{INTRODUCTION}

The development of energy supply systems poses new challenges for planning. Due to the expansion of renewable energies, the trend is increasingly moving from a centralized to a decentralized power supply. Companies are increasingly generating electricity locally, e.g. in their own PV systems. However, this type of generation is highly weather-dependent and therefore not necessarily available when the company needs it. In order to be able to optimally cover the demand for energy at any time, different energy generators and storage facilities are therefore connected to each other to form socalled hybrid systems [1] or integrated energy systems [2], [3], [4]. The operation of hybrid systems is intended to achieve both ecological and economic benefits for the company.

A classic hybrid system, for example, is the combination of a PV system and a battery storage unit. Battery storage systems are short-term storage devices that store electricity for only a few hours or days due to their low storage capacity. However, in order to make better use of the locally generated electricity, the surplus electricity generated from renewable sources in summer would have to be made usable for later winter with a long-term storage facility.

A promising form of long-term storage of overproduced electricity is PtGtP technology [5], [6], [7], in which electricity is converted into hydrogen via an Electrolyzer (ELY), stored in a Hydrogen Storage (HS) and, if required, converted back into electricity via a Fuel Cell (FC).

In politics the topic of hydrogen has taken on an important role in the decarbonisation of the economy. In the context of the G20 summit in Japan (2019), the International Energy Agency has published a report to show the current status of hydrogen and provide recommendations and guidelines for future development [8]. The report notes that clean hydrogen is currently experiencing political and economic momentum and that the number of strategies and projects around the world is increasing dramatically. The report concludes that the technology needs to be expanded and costs reduced in order for hydrogen to be used on a large scale.

Each country is pursuing different strategies and intermediate steps to achieve long-term decarbonisation. Some countries' strategies, such as those of the EU, are based on the assumption that hydrogen will be produced entirely from renewable energies [9], [10]. Germany also aims to import green hydrogen from countries with sunshine such as Africa in order to be able to meet future energy requirements [11]. Other countries such as China [12], [13] are equally striving to produce green and blue hydrogen.

This paper presents a planning tool in the industry and building sector using the example of a dairy in Oldenburg (northwest Germany), where different energy supply concepts with and without hydrogen technologies are integrated, optimised, evaluated and compared. In this way it is shown which supply concepts could be economically and ecologically worthwhile.

First of all, Chapter II presents a detailed literature review of the current state of research on hybrid systems using hydrogen. In chapter III an energy system simulation and design optimisation framework are presented. This framework is demonstrated in Chapter V using a case study of a dairy in Oldenburg, which is briefly introduced in Chapter IV. 


\section{RELATED WORK}

Currently there are many projects concerning the connection of hydrogen technology with distributed energy supply and storage systems. However, the approaches for hydrogen are not new, as these have already been investigated and tested several times in research.

Vosen and Keller [14] mentioned that the hybrid storage options, in which hydrogen and battery storage were used, were already investigated in the 1990s. In their study they investigated the combination of PV, PtGtP (ELY, metal hydride tank and FC) and battery storage via a possible residential design in Arizona, USA. They utilise an algorithm that is programmed so that over time, the program learns to use system resources more efficiently by adjusting the energy storage strategy to fluctuations in power generation and demand. They concluded that using the algorithm, the cost of storing energy for the hybrid system is $48 \%$ of the cost of a hydrogen-only storage option and $9 \%$ of the cost if the storage option were battery only. In addition, this algorithm results in cost savings of $30 \%$ of the storage components compared to a simple state of charge algorithm. They also found that the cost of storage in a DC system is $70 \%$ to $85 \%$ of the cost of an AC system. The sensitivity study shows that the greatest effects of hybrid system cost reduction are the increase in efficiency of energy conditioning and the reduction in the costs of battery, PV, HS and energy conditioning. The algorithm uses storage components more efficiently, resulting in lower storage costs.

Bocci et al [15] also investigated in 2011 a hybrid supply system for a $100 \mathrm{~m}^{2}$ 2-person residential house in Italy (Rome), in which a combination of PV, solar thermal and PtGtP (ELY, metal hydride tank and FC) is used. In addition, the house was newly insulated and all electrical appliances were replaced with more energy-efficient equipment. Radiators were replaced with radiant heating systems and the existing heat pump was replaced with an absorber, as the global efficiency for cooling needs in summer was higher that that of PV and heat pump with a combination of solar thermal and absorber. The study shows that it is possible to reduce the maximum electrical and thermal output as well as the total energy consumption to one third. The hydrogen supply should be a safe and reliable power supply system. While the installation costs are ten times higher than those for batteries or generators, this system is well suited for long-term storage.

In 2014, Zafar and Dincer investigated the combination of PV, Photovoltaic Thermal Hybrid Solar Collector (PVT) and PtGtP [16]. PVT collectors use solar energy to convert it into electricity and heat. The electrical energy generated by the PVT system is used directly for domestic purposes, while excess electricity drives the ELY, generating hydrogen and storing it in a hydrogen container. In the case of the regeneration of electricity using the $\mathrm{FC}$, the heat and water are also used for domestic consumption. They concluded that using the $\mathrm{FC}$ heat also increases energy efficiency from $2.4 \%$ to $5.65 \%$, while exergy efficiency increases from $2.8 \%$ to $19.8 \%$. When looking at the costs, the greater financial advantage is in the use of the heat. The financial benefit of water for drinking water purposes is not very high, but should not be neglected in large-scale applications.

In 2013, Castañeda, Cano et al [17] used a new dimensioning method based on Simulink Design Optimization from MATLAB to perform technical optimisation of hybrid system components consisting of PV, PtGtP, and battery. They followed three control strategies designed to keep the state of charge of each technology at a certain level and to view the overall system from a technical and economic perspective. The dynamic model provided the results that the designed hybrid system provides a reliable power supply but is uneconomical, so that further research in hydrogen technology is needed to develop low-cost and highly efficient hydrogen systems.

Torreglosa, García et al [18] used a novel energy dispatching based on model predictive control for off-grid PV / wind power / PtGtP / battery hybrid systems. In their study they met the objectives of achieving higher global efficiency of the hybrid system, ensuring off-grid load support and keeping the battery state of charge and hydrogen content between the desired operating limits during their long-term simulation which lasted 25 years. The dynamics of the energy sources were neglected and other parameters such as operating costs, deterioration of the sources, state of charge of the storage devices etc. were taken into account.

Another algorithm that minimizes the total system costs based on various assumptions is used by Gillessen, Heinrichs et al [19] 2017, who conducted a case study for a hybrid ELY / battery system in the range of $0.5-3 \mathrm{MW}$ directly coupled to a large PV power plant without grid connection. They investigated the hydrogen production costs of alkaline ELY with different battery types (lithium-ion, vanadium redox flow, zinc-bromine redox flow). They concluded that batteries can adequately support ELY operation, but are associated with higher hydrogen production costs and are not competitive compared to the installation of additional ELY capacity or electricity savings. However, if $100 \%$ renewable energy is desired, the installation of a hybrid battery system with a mixture of different battery types is desirable as it is more cost effective for storage than a solution with only one battery type. The factors that result in this benefit include the ratio of battery capacity to performance and the associated differences in performance and capacity specific investment of the different battery types.

Similar topics on hybrid systems with PtGtP can be found in further literature [20], [21], [22], [23], [24], [25], [26], [27]. In the past, the authors focused heavily on the purely technical feasibility and optimisation, without considering the economics. The ecological aspect was not examined in detail either. They pursued the operating strategy of covering the demand completely energy self-sufficient. They largely agreed that hydrogen, in combination with other technologies, makes the overall system more energy-efficient and is very well suited as a long-term storage medium. In addition, research has also used battery storage as an additional storage medium in order to optimally design the hybrid system. In previous 
researches, hydrogen technology has only been tested for technical feasibility in households and large-scale industry.

In this paper, a planning and modelling tool for energy systems is presented, which does not only focus on the technical feasibility, but also considers the economic and ecological aspects for rather small industrial applications. The case study is aimed at individual buildings or companies. Here, the longterm storage of hydrogen is explicitly considered from both perspectives.

\section{Methodology}

Hybrid distributed energy supply concepts are complex in both planning and operation, detailed analyses and methodologies are required to achieve an overall system behaviour that is worthwhile for the stakeholders involved [28]. According to Schmeling et al [29], the general planning process for distributed energy supply solutions is divided into four phases:

The planning process starts with the determination of the objectives to be pursued (Targeting). These can be of a technical, economic or ecological nature and have to be quantifiable and comparable. In the second phase (Synthesis), all necessary and conceivable technologies are connected to the consumer in unspecified sizes, resulting in a superstructure. In the third phase (Design), different sizes and combinations of technologies are tested in the superstructure in order to minimise or maximise the previously defined objectives. In this process, it is decided which technologies from the superstructure are useful or not. In the last step (Operation), the operational management of the system that has actually been installed at sight is handled and it is ensured that the system runs as optimally and reliably as possible. This step is not a part of this research, since the focus is on the decision-making process up to the realisation.

The first three steps of the methodology are presented in the following and their application to PtGtP technology is examined in more detail.

\section{A. Targeting}

Optimality is always in the eye of the beholder, but must be precisely defined for a successful, objective evaluation of technical systems. The decision problem often cannot be broken to a single factor, but there are different perspectives [30]. For energy technology systems in particular, there is usually a conflict of objectives between costs, environmental impact and technical feasibility, which have to be considered together but are sometimes difficult to compare. This problem can be addressed by carrying out a Multicriterial Optimization (MO) [31], [32], [33].

In general mathematical terms, the subsequent optimisation problem can be described as follows [34]:

$$
\min \left(F(x)=\left(f_{1}(x), f_{2}(x), \ldots f_{\mathrm{N}}(x)\right): x \in X\right)
$$

Here, $x$ describes a possible solution vector of the solution space $X \subset \mathbb{R}^{M}$ with $M$ different degrees of freedom, which is mapped to the $N$ different objectives using the function
$F: \mathbb{R}^{M} \mapsto \mathbb{R}^{N}$ [34]. Whether minimisation or maximisation is carried out is irrelevant, as $\min (F(x))=\max (-F(x))$.

In the end, the MO seeks solutions that are in one way or another better than alternative solutions, i.e. it is not possible to improve one objective function without simultaneously worsening another objective function [35]. Such a solution is called Pareto optimal. Mathematically, this means that for a conceivable solution $\hat{x} \in X$ there is no other solution $x \in X$ for which $f(x) \leq f(\hat{x})$ in the case of a minimisation. The totality of all Pareto optimal solutions then stretches the Pareto front, which in its completeness is the optimal solution of the MO. This can be used for the decision-making process between the various technology alternatives.

For the investigation in this publication, two objective functions are defined which are often used in the evaluation of distributed supply concepts: the annuity according to VDI 2067 [36] and the $\mathrm{CO}_{2}$ emission. These are motivated and specified in more detail below.

1) Economic evaluation: The main goal of every company is to generate as much profit as possible at low cost [37]. From a business management point of view, it is important to cover both the company's energy requirements as much as possible and to achieve this at the lowest possible cost [38]. In order to keep the calculation of the techno-economic evaluation of the supply concepts as simple and comparable as possible, the calculation in this paper is based on the annuity method of the German engineering standard VDI 2067 [36]. The annuity is a repeated annual payment of equal amount, which is required to pay off a system over an observation period. The period under consideration in this case is set at 20 years, as this corresponds to the useful life of the PtGtP system. The expenses are divided into capital-related costs $\left(A_{\mathrm{N}, \mathrm{K}}\right)$, demand-related costs $\left(A_{\mathrm{N}, \mathrm{V}}\right)$, operation-related costs $\left(A_{\mathrm{N}, \mathrm{B}}\right)$ and other costs $\left(A_{\mathrm{N}, \mathrm{S}}\right)$. In addition, the revenues from the sale of energy or from the use of government support measures are added to the calculation and are included in the revenues $\left(A_{\mathrm{N}, \mathrm{E}}\right)$. The annual annuity $\left(A_{\mathrm{N}}\right)$ is calculated from the difference between the revenues and the sum of all cost categories:

$$
A_{\mathrm{N}}=A_{\mathrm{N}, \mathrm{E}}-\left(A_{\mathrm{N}, \mathrm{K}}+A_{\mathrm{N}, \mathrm{V}}+A_{\mathrm{N}, \mathrm{B}}+A_{\mathrm{N}, \mathrm{S}}\right)
$$

According to this method, the energy supply solution with the highest annuity should be realised. In the industry, energy is usually considered a necessary part of the production process, which is why it is not explicitly remunerated, unlike in the housing sector. This usually results in negative annuities, the highest of which is then preferred.

2) Ecological evaluation: In recent years, environmental awareness has become increasingly important for people in Germany [39]. At the same time, the economic valuation of greenhouse gas emission is receiving more attention. $\mathrm{CO}_{2}$ is mainly produced in the energy production process, which is passed along the supply chain to the final consumer. In order to achieve the climate targets, $\mathrm{CO}_{2}$ balancing is necessary as 
it gives consumers or planners of hybrid energy systems the opportunity to design climate-friendly behaviour [40].

The $\mathrm{CO}_{2}$ emission of the energy supply solution is calculated using a balancing boundary approach as described by Wehkamp et al [41]. Boundaries are drawn around the supply object and specific emissions $\left(\mathrm{CO}_{2}\right.$ emission per $\mathrm{kWh}$ consumed) are assigned to energy carriers that flow either into or out of the system, which are in this case Natural Gas (NG) (just in) and electricity (in and out). Since it is assumed in the following that hydrogen is neither exported nor imported, it is not to be considered as an energy carrier. This then only concerns the operational phase and does not take into account the emissions resulting from the manufacture or disposal of the technical components. The specific emissions of solar primary energy are assumed to be zero and those of NG are set at $202 \mathrm{~g} \mathrm{CO}_{2} / \mathrm{kWh}$ [42]. For electricity purchase $E_{\text {Elec }}(t)$, which has a time-varying composition of different energy sources with different emission intensities, a flow tracing method is used to calculate hourly emissions $S_{\text {Elec }}(t)$ [43], [44]. In turn, $\mathrm{CO}_{2}$ is credited by feeding the electricity $E_{\text {Feed }}(t)$ into the public grid [45]. It is not the average German electricity mix that is displaced, but rather the marginal power plant [46]. The value of the emission is defined as the marginal emission, which when averaged over one year gives the displacement mix. This indicates the amount of $\mathrm{CO}_{2}$ per unit of energy that does not have to be emitted due to the substitution of the marginal power plant by the grid feed-in from the Combined Heat and Power (CHP) or PV. According to a forecast, the displacement mix in Germany is expected to be $810 \mathrm{~g} \mathrm{CO}_{2} / \mathrm{kWh}$ in 2020 [47]. Thus, the following formula is used to calculate the annual $\mathrm{CO}_{2}$ emission $C_{\text {Total }}$ of the energy supply solution:

$$
\begin{aligned}
C_{\text {Total }} & =\sum_{t=0}^{T} 202 \frac{g \mathrm{CO}_{2}}{k W h} \cdot E_{\mathrm{NG}}(t)+S_{\mathrm{Elec}}(t) \cdot E_{\mathrm{Elec}}(t) \\
& -810 \frac{g \mathrm{CO}_{2}}{k W h} \cdot E_{\text {Feed }}(t)
\end{aligned}
$$

\section{B. Synthesis}

In the next phase, the superstructure, i.e. the choice of technology and the connections between the technologies are defined. The superstructure of the energy supply solution to be planned is then divided into different scenarios in order to be able to compare the effects of the innovative PtGtP plants with a state-of-the-art system.

1) Scenario 1: Figure 1 shows an energy supply concept that is being implemented in many projects today [48], [49]. This includes a PV system, a battery storage as well as a condensing boiler and a CHP with a short-term Thermal Energy Storage (TES). Via access to the public electricity and NG networks, the necessary energy resources are transmitted to the customer or electricity is fed into the grid. Depending on the market situation, electricity from PV and CHP can be used internally or fed into the grid. In addition, electricity from PV can be temporarily stored in the battery storage. The boiler size is designed for the maximum heat load. In case of a failure of the CHP, the boiler continues to cover the heat demand. It is also used to absorb peak loads. The TES is used exclusively by the CHP. This leads to a decoupling of the electricity and heat generation, so that the CHP can run cost-optimised until the TES is completely filled.

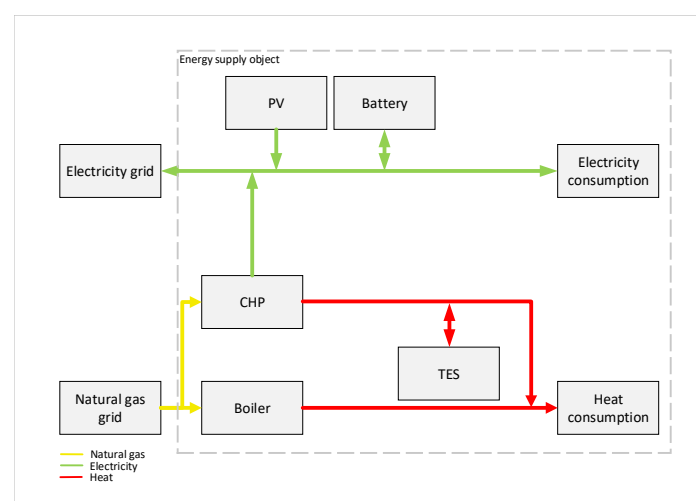

Fig. 1: Scenario 1 with PV, Battery, CHP, TES and boiler. This is a common, distributed supply concept used by companies today and therefore serves as a reference.

2) Scenario 2: In Fig. 2, the hydrogen path, i.e. a ELY, compressed gas storage as HS and a FC, is implemented in the energy supply concept of scenario 1 . In the model it is allowed that the ELY can receive electricity from the different power sources. The ELY does not draw electricity from the battery, as German energy law makes it difficult in this configuration. The hydrogen generated by the ELY has a pressure of 20 bar. It is fed into the HS tank without further compression and, if necessary, is used to generate electricity via the FC. The waste heat from the ELY and the FC is transferred to the heating circuit via heat exchangers to increase the overall efficiency and to use the TES to decouple electricity and heat usage. If the heat cannot be consumed, it is released into the air via a recooling system.

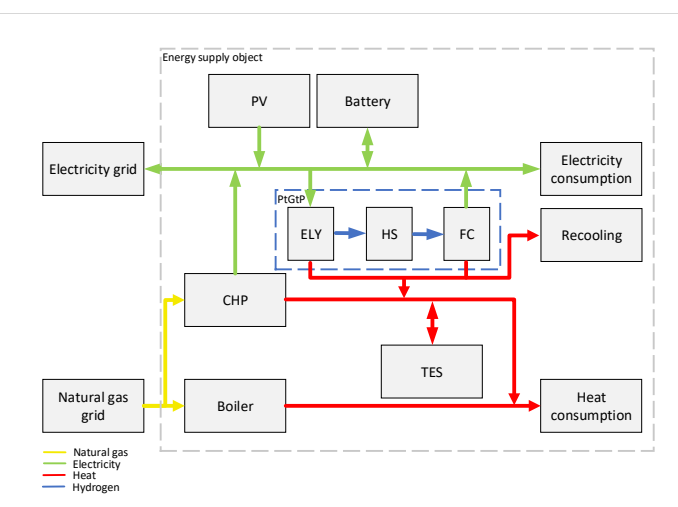

Fig. 2: Scenario 2 additionally with a ELY, HS and FC (PtGtP). The aim is to investigate whether the addition of the PtGtP plant provides an advantage over scenario 1. 


\section{Design}

There are various ways to determine from the superstructure how the optimum system configuration can be designed. In engineering, various methods and rules of thumb are known on how to successfully design the plants according to experience. In such complex systems as the one described here, however, there are often no empirical values and the conventional tools (mostly Microsoft Excel) are not sufficient to make reliable statements. Therefore it is necessary to find new methods that provide reliable results even in such systems. The process developed for this purpose is based on the modelling of the supply concept in a simulation software, which is then used to calculate and evaluate various combinations of plant technology, so called optimal sizing. This results in the system that best achieves the previously defined objectives. The schematic process can be seen in Fig. 3.

1) Optimal Sizing: In the scientific literature, various optimisation algorithms are used to dimension energy generation and storage technology [50], [51]. For most of these methodologies, all components must be modelled continuously in variable sizes. This in turn proves to be difficult in practice, since no continuous plant sizes with standardised properties can be realised, but each manufacturer offers components in fixed sizes and different properties.

For this reason, a brute force approach is chosen here, which does not use intelligent optimisation algorithms to select the sizes, but examines all conceivable sizes and combinations, regardless of their importance. In this way, the various components can be modelled as closely as possible to the manufacturer's technical specifications, but the computational effort of the simulation is significantly higher. Such an approach is possible here because the choice of technologies and also their size represent a relatively small solution space, which can be solved with using modern computer technology and simulation tools.

2) Energy System Simulation: There are several studies concerning simulation software whose main task is to de- termine the optimal dispatch strategy for the combination of different energy systems. Connolly et al [52] compared 37 programmes in 2010 to investigate the integration of renewable energies into different energy systems. The aim was not to find the perfect software, but to get an overview of the software and its individual advantages. Sinha and Chandel [53] examined 19 programmes using a hybrid, distributed energy supply concept. They came to the conclusion that depending on the software, there are considerable differences in the simulation results. Schmeling et al [54] developed a comparison methodology of different commercial simulation tools and find out in the exemplary application to 9 different tools that there are varying recommendations depending on the application case.

The software oemof.solph [55] is used for this publication. This open source tool offers the freedom to define new, innovative components, such as the PtGtP system, and to connect them with existing components such as CHP and battery storage. It also offers various options for defining highresolution input data and analysing the results in detail. It is being continuously developed by a broad community and has already found application in a wide range of research questions (e.g. [56], [57]).

In oemof, energy systems are represented as a directed graph, where the verticies represent either components (sources, sinks, technologies) or buses, which manage the resource flows between the components. The edges are directed and represent resource flows between certain components and buses. This graph is then translated to an Mixed Integer Linear Programming (MILP) problem using pyomo [58] which can be solved numerically by various solvers [59]. The objective is to minimise the costs caused by energy flows in the system while covering all energy demands.

Technologies such as transformers have inflows and outflows, e.g. the consumption of gas from a gas bus to a gas turbine, which then feed electrical energy into an electricity bus. Parameters such as efficiency can be used to determine the ratio of inflow and outflow. Sinks only have inflows

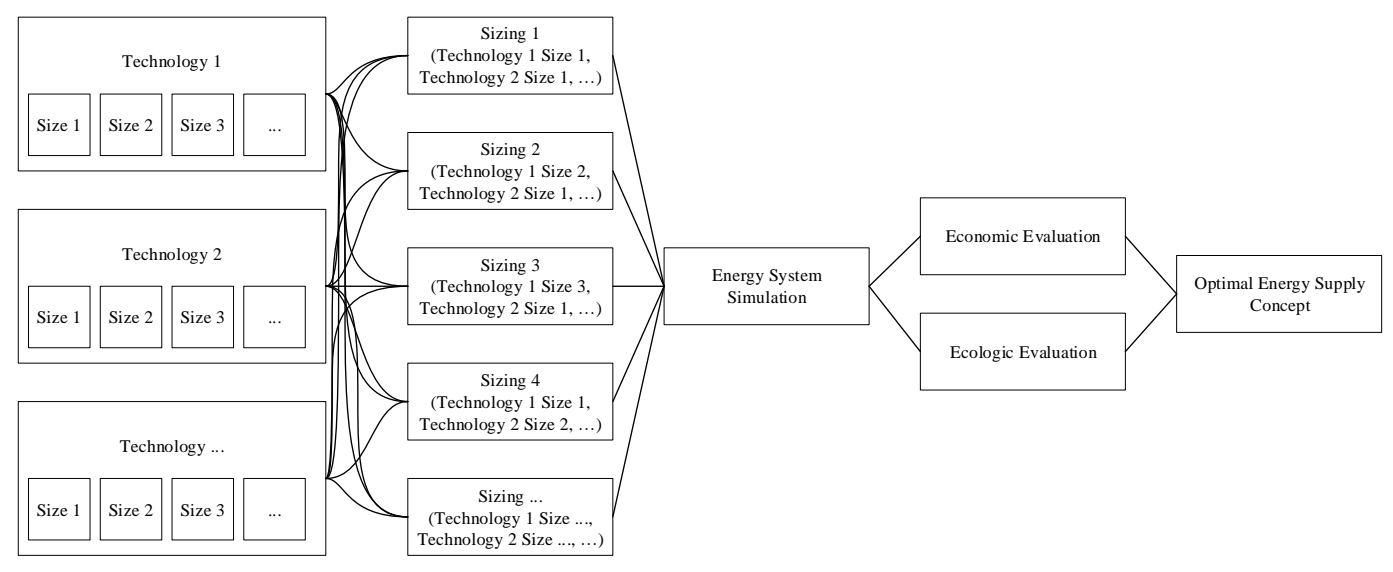

Fig. 3: Representation of the optimum sizing strategy, in which the optimum energy system is determined from different plant sizes with the aid of simulation and evaluation. 
and can represent consumers, e.g. electricity consumption in households. Sources include wind energy or PV systems, but also raw materials and only have outflows. A graphical representation of the oemof model used for scenario 2 can be found in Fig. 4.

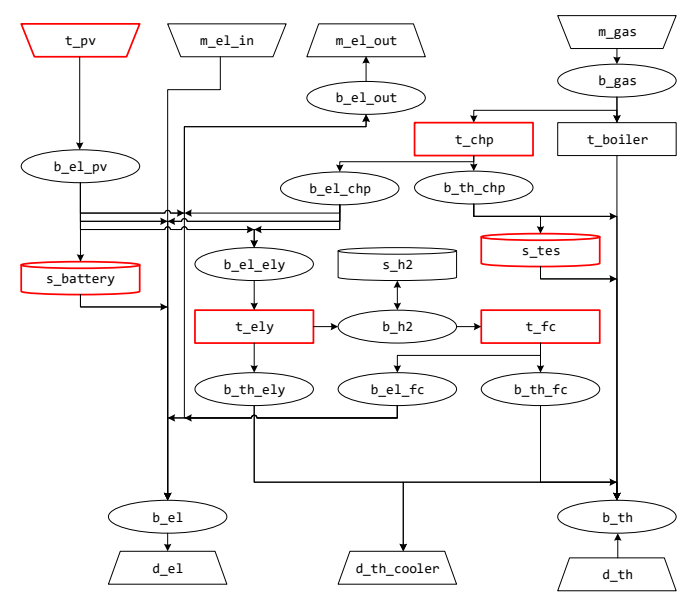

Fig. 4: oemof graph model to simulate scenario 2, where buses are represented as oval, sources and sinks as trapezoids, technologies as rectangles storage systems as cylinders. The nomenclature distinguishes between conversion technologies $\left(t_{\_}\right)$, storages (s_), demands (d_), external markets (m_) and the necessary busses (b_). The components to be optimally sized in the following are marked with a red outline.

3) Modelling the Hydrogen Technologies: As mentioned in Chapter III-C2, the technologies in oemof are modelled as verticies of the energy system graph. This chapter explicitly explains the procedure for modelling the hydrogen technologies, i.e. ELY, HS and FC. All other components used are established technologies and their modelling was carried out with usual processes in oemof, which will therefore not be further presented here.

There are different types for both ELY and FC, which offer different advantages and disadvantages depending on the application. For the intended stationary use in industry, Proton Exchange Membrane (PEM) technology is used for both components of the plant. On one hand, the ELY has the advantages of having no danger of oxygen contamination when operating it under low partial loads, and better management of fluctuating power generation than alkaline ELY. On the other hand, PEM has a significantly higher energy density density (i.e. less floor space required and less material used) as well as greater modularity (e.g. with regard to the caustic preparation of the alkaline electrolysis plants). The PEM FC is very uncomplicated in handling and is particularly suitable for distributed energy supply, since the power output can be controlled with great dynamics. It also has a low temperature working range, for which the waste heat can be ideally used for general heating purposes. The alkaline FC, on the other hand, is higher than the PEM-FC in terms of both construction volume and weight [60].

The intended application is in very small performance classes, so that the PtGtP system can be optimally integrated in small and medium-sized companies. For electrolysis, plants up to $5 \mathrm{~kW}_{\mathrm{el}}$ are used, for FCs up to $8 \mathrm{~kW}_{\mathrm{el}}$. First of all, the data for the creation of the models are taken from the data sheets of the manufacturer. These are the electrical input and output, the thermal output as well as the hydrogen production (ELY) and the hydrogen consumption (FC), respectively, both at full load, minimum partial load and intermediate points. The resulting characteristic curves of hydrogen technologies can be found in the Fig. 5. In good approximation, a linear behaviour between full load and minimum partial load can be assumed. For modelling the two technologies, therefore, the oemof component GenericCHP with the attribute back_pressure=True is chosen. Details on the CHP modelling in oemof can by found in [61], [62].
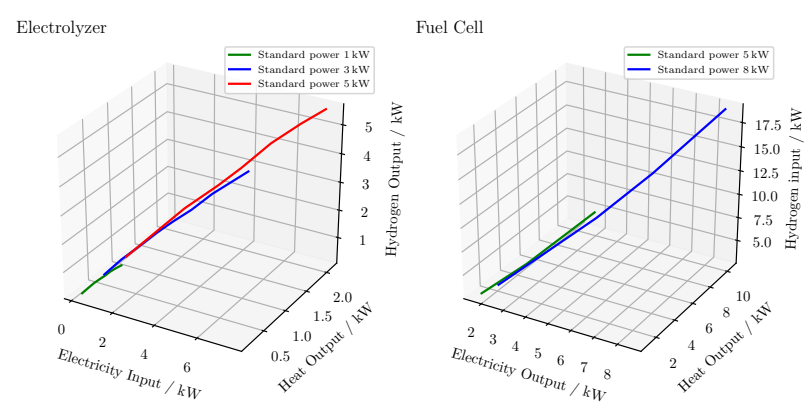

Fig. 5: Characteristic curves of the ELY (left side) and FC (right side).

Gas tanks are used as HS which have a storage capacity per tank of $12.6 \mathrm{~m}^{3}$. The HS is modelled in oemof by the GenericStorage component. The hydrogen is generated by the ELY, which is fed into the hydrogen storage tank without further pressure increase, so without any inflow losses. The FC is also operated at this pressure, which is why there are no outflow losses either. The storage capacity can be calculated with simple physics calculation [63] and is $670 \mathrm{kWh}$ per tank at the set 20 bar. The tanks can be placed next to each other and thus scaled, two HS add up to a storage capacity of $1340 \mathrm{kWh}$. According to the manufacturer, the diffusion of the hydrogen through the wall is negligible so that the storage losses can be assumed to be zero.

\section{Case Study}

In the following, the previously presented methodology will be demonstrated using the example of a dairy. The assumptions of the targeting and synthesis phase are adopted and the optimisation of the design phase is illustrated.

In order to design and optimise this energy system, it is necessary to have detailed information on the energy demand of the energy supply object as well as the prices and remunerations that are applicable under the local energy law for the different energy flows. 


\section{A. Energy supply object}

The dairy is located in the town of Oldenburg in north-west Germany. It is a medium-sized company that is organised as a cooperative and employs about 40 people. Milk is processed into various products such as butter, cream and yogurt, for which electricity and heat are required in various places. In addition, several offices are supplied.

Electricity demand profiles are available as quarter-hourly data $\left(599 \mathrm{MWh}_{\mathrm{el}}\right)$ and heat demand profiles as hourly data $\left(1050 \mathrm{MWh}_{\mathrm{th}}\right)$ for 2016 . The graphic evaluation of the energy demand is shown in Fig. 6. On the load profile (left side) it is clearly visible that both electricity and heat are demanded relatively constant over the year. The load duration curve (right side) represents the power demand in dependence of the utilisation time and is often used for capacity planning of generation plants. Here it can be seen that the electricity and heat demand must be provided in a wide range of capacities, whereby the heat demand usually exceeds the electricity demand. Such a configuration is very well suited for hybrid, CHP-based supply concepts.

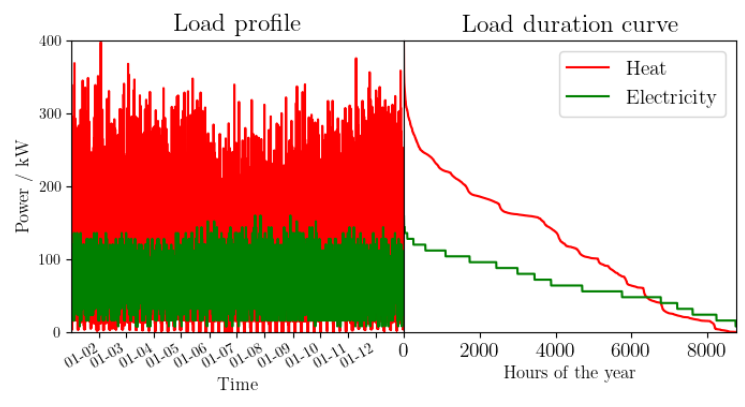

Fig. 6: Energy demand as load curve and load duration curve of the dairy in 2016.

For the installation of PV, the roof area of a gabled roof with a maximum of $200 \mathrm{~m}^{2}$ at $30^{\circ}$ inclination is available. This corresponds to a maximum installed capacity of $40 \mathrm{~kW}_{\mathrm{p}}$. The other system technologies are installed collectively in a machine room, so no further transmission losses have to be considered.
On the basis of this information, the maximum size of the variable technologies are defined, which can be seen in Tab. I. For all plants except the PtGtP plant, zero is assumed as the minimum size in both scenarios. For the PtGtP plant in scenario 2, the minimum plant sizes are defined as the smallest possible value, so their presence is forced in order to see the effects of hydrogen integration.

TABLE I: Minimum and maximum plant sizes of the technologies used for the

optimal sizing.

\begin{tabular}{lc}
\hline Technology & Performance spectrum \\
\hline Boiler / kW & 500 \\
CHP $/ \mathrm{kW}_{\mathrm{el}}$ & $0,50,70,99,134,190$ \\
$\mathrm{PV} / \mathrm{kW}_{\mathrm{p}}$ & $0,10,20,30,40$ \\
TES / m & $0,10,30,50$ \\
Battery / kWh & $0,30,70,131,233$ \\
ELY / kW & $1,3,5$ \\
$\mathrm{HS} / \mathrm{kWh}$ & 670,1340 \\
FC / kW & 5,8 \\
\hline
\end{tabular}

\section{B. Energy prices, taxes and allowances}

In order to be able to determine the costs of the energy supply solutions in the simulations, the energy flows between the verticies have been stored with prices, taxes and remuneration. These are based on the current German legislation and market situation as of 2020. The electricity and NG prices decided by the cost components that correspond to the regional prices at the Oldenburg site. The electricity procurement costs are based on the Day-Ahead price of EPEX SPOT. Capacity charge and energy prices of the grid charges for electricity and gas have been obtained from the local grid operator. Table II shows the prices or remuneration of the technologies' links to each other in the supply object.

\section{RESULTS}

In the following, the methodology developed is applied to the case study shown. The dispatch optimisation of the individual plants with oemof is first demonstrated, followed by the optimal sizing of the relevant components. In order to verify the assumptions of the model and to be able to make recommendations for action, a sensitivity analysis is carried out as a final step.

TABLE II: Price range of the technology paths in $c t \mathrm{kWh}^{-1}$ of the dairy as of January 2020. These are given as a price range, since in the course of the simulations the prices change constantly depending on how, for example, the day-ahead price changes. The technologies on the left are listed as sources, those on the top as sinks. Fields that are physically impossible are greyed out and those that are unregulated are highlighted in white and marked with a minus. Connections that are technically possible but are disregarded for this study are marked with an X. Revenues are positive and expenditures negative.

\begin{tabular}{|l|c|c|c|c|c|c|c|}
\hline Source Sink & Elec. grid & Battery & PtGtP & El. cons. & CHP & Boiler & Th. cons. \\
\hline Elec. grid & & $\mathrm{X}$ & $-21.43-3.97$ & $-23.48-1.92$ & & & \\
\hline PV & $10.06-10.27$ & 0 & 0 & -2.70 & & & \\
\hline Battery & $\mathrm{X}$ & & $\mathrm{X}$ & -2.70 & & & \\
\hline PtGtP & $-10.49-13.01$ & $\mathrm{X}$ & & -2.70 & & & \\
\hline NG grid & & & & & $-5.95--4.59$ & $-5.95--4.59$ & \\
\hline CHP & $-9.83-21.01$ & & $0-4.00$ & $-2.70-1.30$ & & - \\
\hline Boiler & & & & & & - \\
\hline
\end{tabular}




\section{A. Optimal Dispatch}

The simulation per plant configuration is run for one year and then evaluated with the objectives introduced in Sec. III-A. The schedules are selected in such a way that the costs for the operator are kept to a minimum over the period under consideration.

Figure 7 exemplifies the plant behaviour of the technologies for one week. Here it can be observed that especially on weekends the heat demand often falls to zero, so that the heat from the TES or CHP unit is not needed. During this time, the CHP is operated electricity driven, i.e. the majority of the CHP electricity is used to cover the electricity demand. This leads to the fact that the TES is completely filled with the heat from the CHP, so that the complete heat supply could be covered by the TES in a short time. At this time the CHP unit is switched off. During this time, the electricity demand is covered by the PV system and the battery storage. During the week, electricity and heat are required at any time of the day, which can be covered well due to the flexibility of the CHP unit with its partial load range. The figure shows that the heat demand during the time of day, i.e. during production time, is covered by the CHP and supported by the TES. After production time, the TES is refilled by the CHP unit to use it again the next day to cover peak loads. The boiler is not used at all in this time frame. Unused CHP electricity is fed into the public grid, so that in addition to the reduction of the grid load, a significant reduction of $\mathrm{CO}_{2}$ emissions is the result. Small, almost non-visible amounts of CHP electricity are converted into hydrogen. The PV system generates a small amount of electricity during the daytime, with part of the electricity used in the morning. In the afternoon, another part of the electricity is fed into the public grid and another part is stored in the battery. Minimal amounts are converted into hydrogen as well. The supply of heat from the ELY and the FC is almost irrelevant. The electricity from the FC is used for the electricity demand in the production period, where high load peaks occur. It can be observed that the amount of hydrogen in the hydrogen storage slowly decreases. In order to be able to cover the peaks completely, electricity from the public grid is used.

Figure 8 shows the SOCs of electricity, heat and hydrogen storage systems over a period of one year for the same examplary configuration. Here, the heat storage system is fluctuating by a large amount, as it is constantly supplied with heat by the CHP. The battery storage unit also experiences much frequent cycles. The hydrogen storage system, on the other hand, is less fluctuating. During spring, the hydrogen storage tank is filled with hydrogen and stored over the summer. Towards fall and winter, it is gradually stored out, which serves to cover the electricity demand.

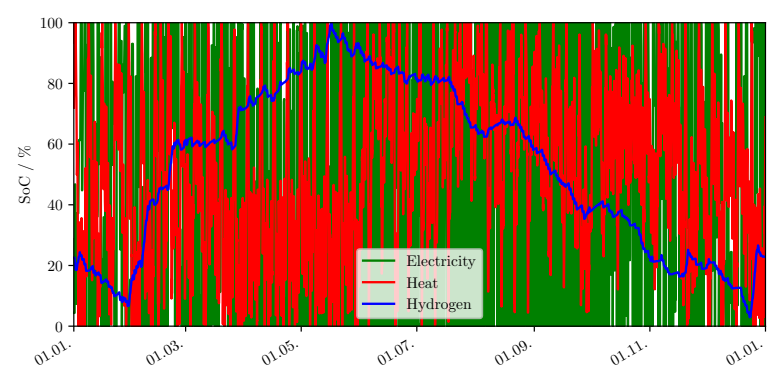

Fig. 8: This figure shows the percentage SOCs of the various storage systems from the configuration in Fig. 7 over the year.

\section{B. Multi-Criteria Optimal Sizing}

As described in Chapter III-C1, the technology sizes are changed in the course of the simulation, so that different combination possibilities of the technologies are iterated. A maximum computing time of $2.5 \mathrm{~h}$ per sizing was set, but this

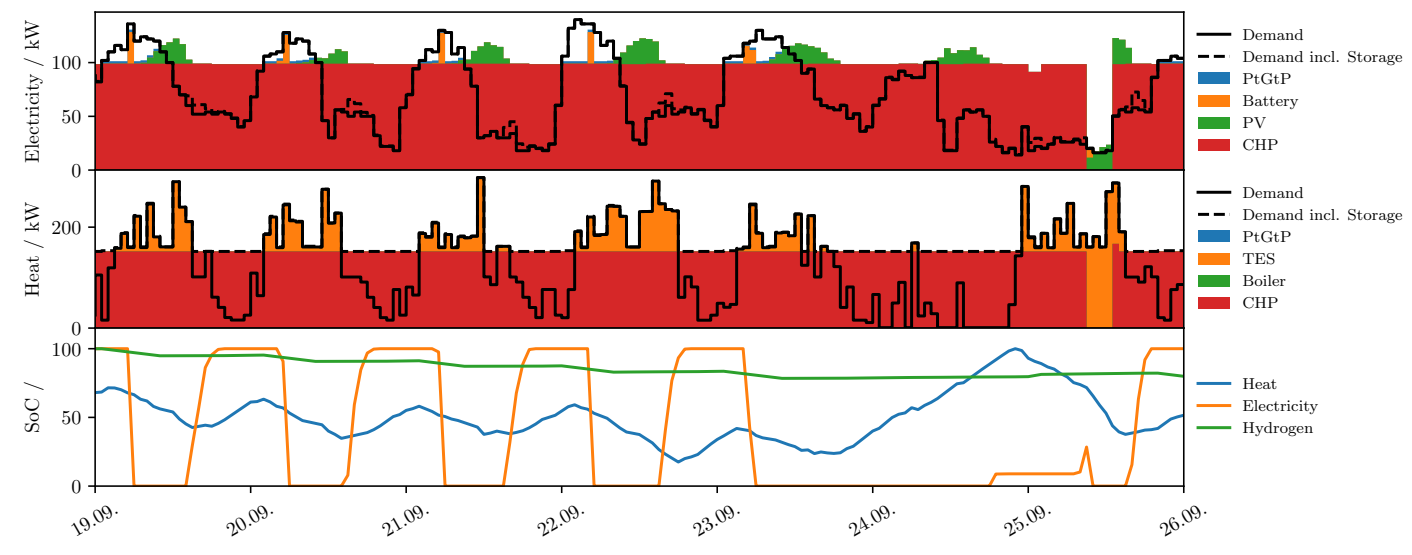

Fig. 7: Exemplary presentation of dispatch optimisation for a one week (Monday - Sunday) timeframe and an exemplary configuration (CHP $99 \mathrm{~kW}_{\mathrm{el}}$, PV $40 \mathrm{~kW}_{\mathrm{p}}$, TES $50 \mathrm{~m}^{3}$, battery $30 \mathrm{kWh}$, ELY $5 \mathrm{~kW}_{\mathrm{el}}$, HS $1340 \mathrm{kWh}, \mathrm{FC} 8 \mathrm{~kW}_{\mathrm{el}}$ ). Electricity consumption and production (top), heat consumption and production (middle) and the State of Charge (SOC) of all storages (bottom) are shown. 
was rarely used. In addition, different sizings were computed in parallel on different threads, which was easily possible due to the choosen brute force approach. The complete optimisation of both scenarios needs about $140 \mathrm{~h}$ or 6 days on a modern desktop PC.

The resulting objectives per sizing can then be combined and further analysed in the form of a pareto front. The paretooptimal results are shown graphically as a red front for the two scenarios (see Fig. 9 and 10). The size of the CHP unit, which of all technologies has the greatest influence on the objectives, is also shown.

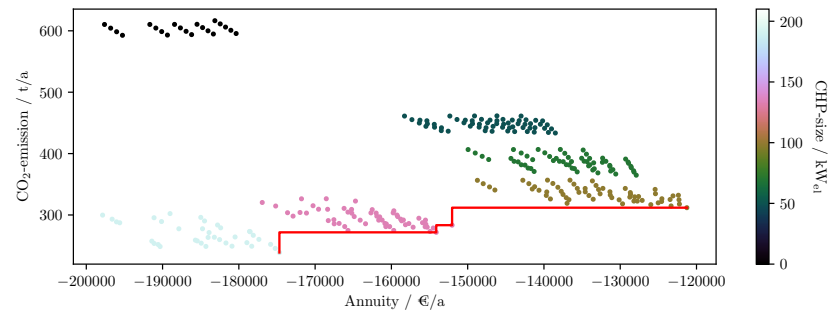

Fig. 9: Illustration of the results from scenario 1 as a scatter diagram. It shows the Pareto front (red) between annuity and $\mathrm{CO}_{2}$ emission. The corresponding plant sizes of the CHP are shown in colour. Here it can be seen that from a CHP size of $99 \mathrm{~kW}_{\mathrm{el}}$ the optimum results are achieved.

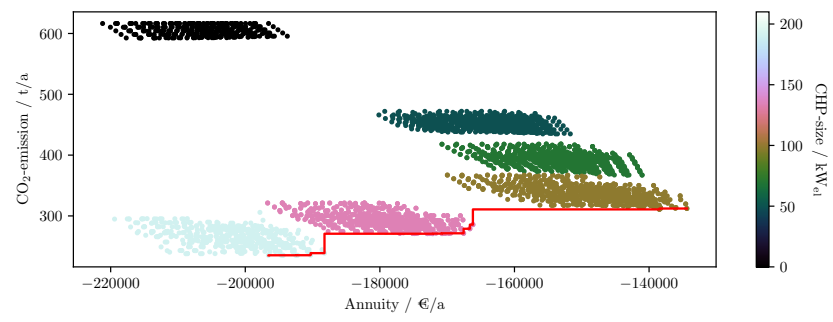

Fig. 10: Illustration of the results from scenario 2 as a scatter diagram. It shows the pareto front (red) between annuity and $\mathrm{CO}_{2}$ emission. The corresponding plant sizes of the CHP were shown in colour. Here you can see that an CHP size of $99 \mathrm{~kW}$ el is both economically and ecologically the best solution.

In Fig. 9 the results of the calculations of scenario 1 are shown as points in the scatter diagram. The $\mathrm{X}$ axis corresponds to the annuity and the $\mathrm{Y}$ axis to the $\mathrm{CO}_{2}$ emission. As a further dimension, the dots are highlighted in colour depending on the electrical CHP output. The diagram shows that in each point cloud a certain CHP unit size dominates. At the top left of the picture a cloud of points is shown where no CHP (CHP output $0 \mathrm{~kW}_{\mathrm{el}}$ ) has been implemented in scenario 1. By increasing the CHP output, the point cloud moves towards the bottom right. This means that the energy supply concept becomes cheaper and produces fewer emissions. From a CHP output of $99 \mathrm{~kW}_{\mathrm{el}}$, a tipping point is reached in which the energy supply concept becomes lower in emissions but immediately more expensive.
From this point on, the Pareto-optimal results, i.e. the optimal energy supply solutions, are shown as a Pareto-front (red).

The course of scenario 2 (see Fig. 10) looks very similar to scenario 1. By adding the hydrogen technologies, the point clouds are correspondingly larger, since the combination possibilities are much more extensive. Here it can also be seen in the Tab. III that no significant improvement is to be seen with regard to the emission values. Due to the increased investment expenditure with hydrogen technologies, the annuities have increased accordingly. For the most part, the low power levels of hydrogen technology are the most optimal results.

TABLE III: Multi-criteria decision matrix from the results of the Pareto front of both scenarios

\begin{tabular}{|c|c|c|c|c|c|c|c|c|c|}
\hline & $\begin{array}{l}\text { CHP } \\
\mathrm{kW}_{\mathrm{el}}\end{array}$ & $\begin{array}{r}\mathrm{PV} \\
\mathrm{kW}_{\mathrm{p}}\end{array}$ & $\begin{array}{l}\text { TES } \\
\mathrm{m}^{3}\end{array}$ & $\begin{array}{c}\text { Battery } \\
\text { kWh }\end{array}$ & $\begin{array}{l}\text { ELY } \\
\mathrm{kW}_{\mathrm{el}}\end{array}$ & $\begin{array}{c}\mathrm{HS} \\
\mathrm{kWh}\end{array}$ & $\begin{array}{c}\mathrm{FC} \\
\mathrm{kW}_{\mathrm{el}}\end{array}$ & $\begin{array}{c}\text { Annuity } \\
€ / \mathrm{a}\end{array}$ & $\begin{array}{c}\mathrm{CO}_{2} \text {-emission } \\
t / \mathrm{a}\end{array}$ \\
\hline & 99 & 40 & 50 & 0 & 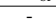 & - & 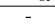 & -121263 & 312 \\
\hline 을 & 134 & 20 & 50 & 0 & - & - & - & -152043 & 283 \\
\hline चี & 134 & 40 & 50 & 30 & - & - & - & -154122 & 272 \\
\hline & 190 & 40 & 50 & 0 & - & - & - & -174683 & 239 \\
\hline & 99 & 40 & 50 & 0 & 1 & 670 & 5 & -134384 & 312 \\
\hline & 99 & 40 & 50 & 0 & 1 & 1340 & 5 & -138463 & 311 \\
\hline & 134 & 30 & 30 & 0 & 1 & 670 & 5 & -166177 & 286 \\
\hline & 134 & 40 & 30 & 0 & 1 & 670 & 5 & -166628 & 279 \\
\hline & 134 & 40 & 50 & 30 & 1 & 670 & 5 & -167556 & 271 \\
\hline 임 & 134 & 40 & 50 & 0 & 3 & 670 & 5 & -170751 & 271 \\
\hline ]ี & 134 & 40 & 50 & 0 & 1 & 1340 & 8 & -172152 & 271 \\
\hline & 190 & 40 & 50 & 0 & 1 & 670 & 5 & -188228 & 239 \\
\hline & 190 & 40 & 50 & 0 & 3 & 670 & 5 & -190295 & 235 \\
\hline & 190 & 40 & 50 & 0 & 1 & 670 & 8 & -192218 & 235 \\
\hline & 190 & 40 & 50 & 0 & 5 & 670 & 5 & -192457 & 235 \\
\hline & 190 & 40 & 50 & 0 & 5 & 1340 & 8 & -196565 & 235 \\
\hline
\end{tabular}

These results are then converted into a "multi-criteria decision matrix" (Tab. III). It is a complete listing of the pareto-optimal results with the respective technology sizes, annuities and emission values in the overview. The results are arranged in such a way that the most economical but also most emission-intensive energy supply solution is at the top and the most cost-intensive, low-emission energy supply solution is at the bottom. The decision-maker thus has a choice that enables it to weigh up which variant appears most sensible to it, whether it is the most economical, the low-emission or a compromise of the two variants.

For the paper, two scenarios were presented, one with PtGtP and one without, to make the differences clear. Between the scenarios, it can be seen that the scenario without PtGtP is more favourable than with the technology. The emission values deviate slightly in some cases. It can be seen that from a CHP unit size of $99 \mathrm{~kW}_{\mathrm{el}}$ upwards the energy system is paretooptimal, i.e. a lower CHP unit output is not meaningful in this case study. Furthermore, it can be seen that the low output sizes of hydrogen technologies are usually the most optimal results in terms of economic efficiency. The increase in the performance parameters of PtGtP does not result in any significant changes in emission values. The annuity increases very strongly in relation to the emission values. It is noticeable that in both scenarios a battery is only useful in a certain constellation of technologies. Otherwise a battery has no further use in this case study.

\section{Sensitivity analysis}

A key challenge for any company is to make decisions in the face of uncertainty, which can turn out to be either an 
opportunity or a risk for them. An unpredictable future and its consequences are difficult to assess. If decisions are to be made, appropriate methods must be used to determine sound estimates and trade-offs between the effects on the company [64].

In the present study after the integration of PtGtP plants into distributed generation structures, the question arises as to which parameters would have to change in order to modify the statements made before. To analyse this, a sensitivity analysis is carried out in the following to identify key parameters that have an impact on the overall system. The sensitivity analysis is a decision methodology that tests the sensitivity of a calculation result to variations of the input parameters of the calculation [65], [66], [67]. This is often included in the economic efficiency calculation in order to consider the change of the calculation result under a given deviation of the key parameters. In this case, one key parameter is changed while retaining the other key parameters.

1) Identification of key parameters: The following parameters in bold are subject to a variability of $-100 \%$ to $100 \%$ or partly smaller changes.

Electricity and NG prices depend not only on very volatile international trading markets but also, and above all, on national legislation and therefore change frequently and with little predictability. This includes not only procurement prices, but also subsidies for feeding locally generated electricity into the grid (PV and CHP feed-in tariff). In Germany, the EEG levy, used to fund renewable energy subsidies, is a matter of great debate. This levy has risen sharply in recent years and is payable, for example, on electricity generated in-house as well.

In addition to these more energy-economic factors, this section will also look at changes in energy technology, especially efficiency improvements in ELY and FC and changes in PV electricity production, as would be possible, for example, by relocating.

For the sensitivity analysis, the technologies of the most economical solution of scenario 3 are used, application to other sizings gives similar results. Figure 11, 12 and 13 show the results of the sensitivity analysis as a function of variability.

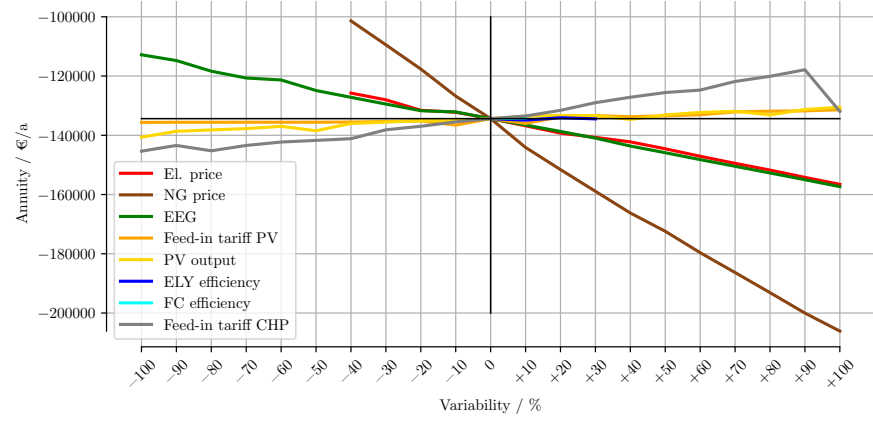

Fig. 11: Sensitivity analysis of the annuity as a function of the variability of key parameters from the dairy case study

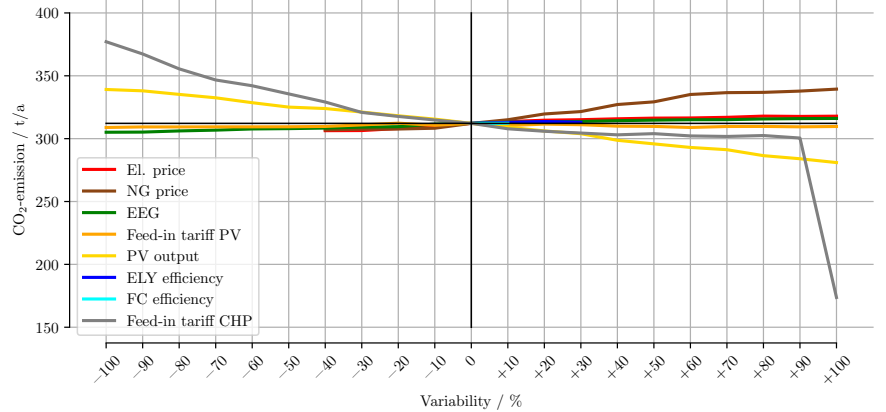

Fig. 12: Sensitivity analysis of the $\mathrm{CO}_{2}$ emission as a function of the variability of key parameters from the dairy case study

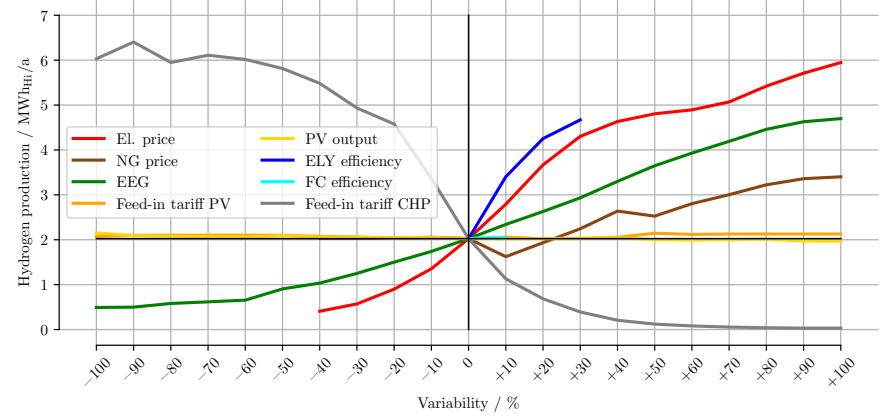

Fig. 13: Sensitivity analysis of the hydrogen production as a function of the variability of key parameters from the dairy case study

In the evaluation, the key parameters and the effects on the energy system are explained one after the other.

The sensitivity analysis shows for the annuity (see Fig. 11) that the most sensitive key parameter is the price of NG. The line is relatively constant and primarily affects the operating behaviour of the CHP. At the same time, the boiler is also operated minimally more. If the NG price rises, the annuity increases considerably and $\mathrm{CO}_{2}$ emissions rise by around 30 t/a (see Fig. 12). Hydrogen production is initially reduced when the price of natural gas rises by ten percent because less CHP electricity flows to the ELY (see Fig. 13). From a ten-percent increase in efficiency, this can be explained by the fact that the use of electricity and waste heat from the ELY and FC is more important than the heat use of the CHP. If the price of NG falls, the annuity decreases significantly, but nothing changes in $\mathrm{CO}_{2}$ emissions and hydrogen production. This is due to the fact that the operating behaviour of the CHP unit has not changed in terms of NG consumption, and only the reduction in the price of NG makes up this difference in annuity.

For the electricity price, the course of the annuity is flatter for the NG price (see Fig. 11). As the electricity price increases, the amount of electricity from the grid slowly decreases. The biggest cost increase is the German Renewable Energy Sources Act (EEG) cost of electricity from the CHP to 
cover the electricity demand. In addition, hydrogen production continues to rise as the ELY is supplied with PV and CHP electricity (see Fig. 13). If the price of electricity falls, less and less PV and CHP electricity is used for hydrogen production, because feeding it into the public grid is more economical than obtaining electricity from the FC. This also leads to a little more $\mathrm{CO}_{2}$ being credited (see Fig. 12).

The course of the EEG levy is similar to the electricity price in terms of annuity and $\mathrm{CO}_{2}$ emissions (see Fig. 11). When the EEG is reduced, larger amounts of electricity are fed from the PV system into the public grid. The amount of electricity from the CHP for the ELY also decreases slowly, so the electricity is fed into the public grid instead. This in turn leads to higher $\mathrm{CO}_{2}$ emission. Furthermore, the amount of electricity from the public grid for both the ELY and the electricity demand is slowly increasing. If the EEG is completely omitted, a large part of the PV electricity is fed into the grid. The reason is that in addition to the reduction of the EEG through the exchange price, the electricity price reaches such a low level that it is more economical to feed PV electricity into the grid and receive compensation for it, in order to then purchase electricity from the grid at a favourable price. If, on the other hand, the EEG increases, more CHP and, to a minimum, PV electricity will be used for hydrogen production.

The variability of the PV output has little effect on the annuity (see Fig. 11). The increase in PV output leads to an increase in the amount of electricity fed into the grid and thus to an increase in the remuneration for the electricity. In addition, the feed-in to the grid reduces the emission values (see Fig. 12). The reduction of the PV output leads accordingly to the opposite. It has hardly any influence on the production of hydrogen (see Fig. 13).

The reduction of the feed-in tariff on the annuity is at a lower rate than on the PV output, but increases slowly (see Fig. 11). The incentive to feed PV electricity into the public grid gradually decreases. In the end, PV electricity is used almost exclusively for self-consumption. This increases the amount of CHP electricity that is fed into the public grid. The emission values hardly change (see Fig. 12). It also has hardly any effect on hydrogen production (see Fig. 13). On one hand, a little more PV electricity is used for hydrogen production, while on the other hand less CHP electricity is used for this purpose. The increase in the feed-in tariff has a similar increase in annuity as the PV output, as it is more economical to feed a higher amount of PV electricity into the grid. There is little change in emissions, as almost the same amount of electricity is drawn from the grid to cover electricity demand. Hydrogen production increases minimally from $50 \%$ onwards, as a higher amount of CHP electricity is used.

The variability of CHP feed-in tariff has a large impact on the emission value and on hydrogen production, but little impact on the annuity (see Fig. 11). Instead, when CHP feedin tariff is reduced, more CHP electricity is used for hydrogen production, which is discontinuous from below $-20 \%$ (see Fig. 13). In addition, the amount of electricity generated by the CHP unit is reduced, which means that less electricity is fed into the grid, thus increasing the emission value. If, however, CHP feed-in tariff increases, the amount of electricity from the CHP to the ELY decreases and less hydrogen is produced. In addition, the amount of electricity from the CHP unit that is fed into the electricity grid gradually increases. If the CHP feed-in tariff increases by $100 \%$, the entire CHP electricity flows into the electricity grid, so that a high $\mathrm{CO}_{2}$ credit takes place at the same time (see Fig. 12). However, in order to be able to cover the electricity demand, large amounts of electricity are drawn from the public grid, so that the annuity increases again.

Changing the efficiency of the ELY has no effect on annuity (see Fig. 11) and emissions (see Fig. 12). In the illustration of hydrogen production (see Fig. 13), only an electrical efficiency increase of $30 \%$ is possible to achieve almost $100 \%$ electrical efficiency. The $30 \%$ efficiency increase of the ELY increases the hydrogen production by about $2.6 \mathrm{MWh}_{\mathrm{H}_{\mathrm{i}}}$, which is not only due to the efficiency increase, but also a higher amount of electricity from the CHP that is fed into the ELY.

The increase in FC efficiency from $90 \%$ to $100 \%$ has no effect on annuity (see Fig. 11) and emissions (see Fig. 12). There is also no increase in hydrogen production (see Fig. 13).

\section{DISCUSSION}

As shown in the results discussed in the previous chapter, the planning of distributed energy supply concepts using PtGtP as seasonal storage is multi-layered and complex. The presented planning tool using an energy system simulation and multi-criteria decision tools can be seen as a helpful supplement in the market establishment of such systems.

Thus it can be clearly seen (cf. Fig. 8) that the combination of different storage technologies with different time horizons and efficiencies during operation can fulfil their intended tasks well in order to keep the local system efficient and optimal. The energy simulation shows very well how in hybrid, sector-coupled systems, the energy-generating and energy-storage plants complement each other depending on the market situation and framework conditions in order to generate an advantage for companies, taking benefit of the national regulatory framework.

The simulation offers insights into the system that would not be possible with classical planning tools. Due to the exclusive use of open source software, which can be easily adapted and individualised, allows the results to be integrated into existing planning processes and used to investigate other academic and business questions.

Nevertheless, the results of this simulation should be treated with caution, as a number of simplifications have been made, which in the end are decisive for real operation. On the thermal side, the system only calculates energy quantities in $\mathrm{kWh}$ without considering the actual restrictions caused by different temperatures in the supply and return flow. Likewise, only hourly averages are simulated, but the system behaviour within these time steps can deviate massively and have a negative influence on the system. Furthermore, the simulation always assumes a perfectly predictable future, where weather changes 
and stock exchange prices are always known, which simplifies the use of seasonal storage tremendously. For the use of such a system in the field, an intelligent and dynamic energy management is therefore indispensable.

The optimal sizing based on this simulation and utilising a brute force optimisation of all technical systems offers further insights into the dynamics of the system. The possibility to compare different designs automatically and individually is a great advantage in decision-making. Not only can the technologies be individually adapted and extended, but also different national or regional framework conditions or objectives can be inserted and examined. For the case study examined and under the current framework conditions, it could be clearly established that PtGtP in its entirety would only be pareto-optimal with a very high $\mathrm{CO}_{2}$ focus compared to a classic CHP-based system. Although the simulation finds times when the operation of the PtGtP plant offers added value, the high investment costs make the system not worthwhile.

The main disadvantage of the approach chosen here is the brute force approach, which allows to model the systems as close as possible to the manufacturer's specifications, but increases the computing time extremely. Furthermore, one is very limited in the choice of the specific manufacturer. This could be solved by an integer based approach, in which a large number of different plants of different manufactures are modelled, put in a meaningful order, numbered and calculated with integer non-linear optimiser.

By adding a sensitivity analysis to the methodology, more in-depth findings can be derived, including specific recommendations for action. For the case study, it can be seen that an increase in the efficiency of technical installations has a relatively small effect. On the other hand, the use of PtGtP can be specifically promoted by a clever change in the political framework conditions.

But even these statements are only half the truth, since in this classical sensitivity analysis it was assumed that only one parameter changes at a time. In the real market, for example, an increase in the price of NG also directly changes the price of electricity and the abolition of the EEG levy would also lead to a reduction in the PV feed-in tariff. However, when looking at the results of hydrogen production, it is clear that several, well-aligned changes would be needed to achieve a significant effect.

For example, a Monte Carlo Simulation could be used for this purpose, in which a large number of different scenarios can be built and analysed using statistical future models of the parameters and their correlation [66], [68]. This would give more reliable and better information on Key Performance Indicators (KPIs), as it would provide a large amount of information and reflect realistic modelling. A major disadvantage, however, would be the high computational time and the high modelling effort.

\section{CONCLUSION}

This paper presented a planning tool for hybrid, distributed energy systems and highlighted the use of PtGtP systems.
After a detailed literature research on the integration of hydrogen technologies in energy systems, the methodology for the planning process was explained. For the investigation the oemof was used via the programming language Python to create the energy system model. A dairy serves as a case study, where the energy data of the dairy as well as remuneration and prices according to the German energy law were modelled in the energy system simulation. Over an observation period of one year with a useful life of 20 years, different plant sizes were iterated and the pareto-optimal solutions with regard to the economic and ecological aspects were determined, which are listed in a multi-criteria decision matrix. A sensitivity analysis was conducted to determine future opportunities or risks of hydrogen technology. For this purpose, key parameters were identified and individually varied. The results, which were drawn up as examples for the previously optimised dairy, show the effects of the key parameters.

It has been shown that hybrid, distributed energy systems provide worthwhile added values for companies in terms of economic efficiency and emission values. A CHP unit, especially, has a considerable positive influence on both target functions. The use of PtGtP in this energy system is not suitable at the present time since, in addition to the excessively high investment costs, the energy law framework has not yet been appropriately coordinated. A significant effect can be achieved by specifically changing the parameters. Government support measures and changes in the law would be useful here, so that a commercial energy supply with PtGtP can be achieved.

\section{ACKNOWLEDGMENT}

This research was partially funded by the Federal Ministry for Economic Affairs and Energy (BMWi) and the Federal Ministry of Education and Research (BMBF) of Germany in the project ENaQ (project number 03SBE111).

\section{ABBREVIATION}

$\begin{array}{ll}\text { CHP } & \text { Combined Heat and Power } \\ \text { EEG } & \text { German Renewable Energy Sources Act } \\ \text { ELY } & \text { Electrolyzer } \\ \text { FC } & \text { Fuel Cell } \\ \text { HS } & \text { Hydrogen Storage } \\ \text { KPI } & \text { Key Performance Indicator } \\ \text { MILP } & \text { Mixed Integer Linear Programming } \\ \text { MO } & \text { Multicriterial Optimization } \\ \text { NG } & \text { Natural Gas } \\ \text { PEM } & \text { Proton Exchange Membrane } \\ \text { PtGtP } & \text { Power-to-Gas-to-Power } \\ \text { PV } & \text { Photovoltaic } \\ \text { PVT } & \text { Photovoltaic Thermal Hybrid Solar Collector } \\ \text { SOC } & \text { State of Charge } \\ \text { TES } & \text { Thermal Energy Storage }\end{array}$

\section{REFERENCES}

[1] J. F. Manwell, "Hybrid Energy Systems," Encyclopedia of Energy, vol. 3, pp. 215-229., 2004 
[2] H. Lund and E. Münster, "Integrated energy systems and local energy markets," Energy Policy, vol. 34, no. 10, pp. 1152-1160, 2006.

[3] L. Bai, F. Li, H. Cui, T. Jiang, H. Sun, and J. Zhu, "Interval optimization based operating strategy for gas-electricity integrated energy systems considering demand response and wind uncertainty," Applied Energy, vol. 167, pp. 270-279, 2016.

[4] P. C. Loh, L. Zhang, and F. Gao, "Compact integrated energy systems for distributed generation," IEEE Transactions on Industrial Electronics, vol. 60, no. 4, pp. 1492-1502, 2013.

[5] P. P. Edwards, V. L. Kuznetsov, W. David, and N. P. Brandon, "Hydrogen and fuel cells: Towards a sustainable energy future," Energy Policy, vol. 36 , no. 12 , pp. $4356-4362,2008$.

[6] U. Eberle, M. Felderhoff, and F. Schüth, "Chemical and physical solutions for hydrogen storage," Angewandte Chemie (International ed. in English), vol. 48, no. 36, pp. 6608-6630, 2009.

[7] M. Sterner and I. Stadler, Energiespeicher - Bedarf, Technologien, Integration. Berlin, Heidelberg: Springer Berlin Heidelberg, 2017.

[8] International Energy Agency (IEA), "The Future of Hydrogen: Seizing today's opportunities," Paris, 2019. [Online]. Available: https://www.iea.org/reports/the-future-of-hydrogen

[9] A. Floristran, N. Brahy, N. Kraus, S. Skiker, S. Damman, D. Hayter, and D. Nozharova, "HyLaw - EU Policy Paper," 2019. [Online]. Available: https://www.hylaw.eu/sites/default/files/2019-06/EU\%20Pol icy\%20Paper\%20\%28June\%202019\%29.pdf

[10] Fuel Cells and Hydrogen 2 Joint Undertaking, Hydrogen Roadmap Europe: A sustainable pathway for the European energy transition. Luxembourg: Publications Office of the European Union, 2019.

[11] FuelCellsWorks, "Germany: Hydrogen Partnership with Africa Begins," 11. February 2020. [Online]. Available: https://fuelcellsworks.com/new s/germany-hydrogen-partnership-with-africa-begins/

[12] Z. Liu, K. Kendall, and X. Yan, "China progress on renewable energy vehicles: Fuel cells, hydrogen and battery hybrid vehicles," Energies, vol. 12, no. 1, p. 54, 2019.

[13] The Energy and Resources Institute, National Centre for Climate Change Strategy and International Cooperation, Central University of Finance and Economics, Zhejiang University, United Nations Development Programme and Shakti Sustainable Energy Foundation, "Low carbon development in china and india," 2016. [Online]. Available: https://www.undp.org/content/dam/china/docs/Publications/U NDP-CH-EN\%20china-india\%20low\%20car-bon\%20report.pdf

[14] S. Vosen and J. Keller, "Hybrid energy storage systems for stand-alone electric power systems: optimization of system performance and cost through control strategies," International Journal of Hydrogen Energy, vol. 24, no. 12, pp. 1139-1156, 1999.

[15] E. Bocci, F. Zuccari, and A. Dell'Era, "Renewable and hydrogen energy integrated house," International Journal of Hydrogen Energy, vol. 36, no. 13, pp. 7963-7968, 2011.

[16] S. Zafar and I. Dincer, "Thermodynamic analysis of a combined pv/tfuel cell system for power, heat, fresh water and hydrogen production," International Journal of Hydrogen Energy, vol. 39, no. 19, pp. 99629972, 2014.

[17] M. Castañeda, A. Cano, F. Jurado, H. Sánchez, and L. M. Fernández, "Sizing optimization, dynamic modeling and energy management strategies of a stand-alone pv/hydrogen/battery-based hybrid system," International Journal of Hydrogen Energy, vol. 38, no. 10, pp. 3830-3845, 2013.

[18] J. P. Torreglosa, P. García, L. M. Fernández, and F. Jurado, "Energy dispatching based on predictive controller of an off-grid wind turbine/photovoltaic/hydrogen/battery hybrid system," Renewable energy, vol. 74, pp. 326-336, 2015.

[19] B. Gillessen, H. U. Heinrichs, P. Stenzel, and J. Linssen, "Hybridization strategies of power-to-gas systems and battery storage using renewable energy," International Journal of Hydrogen Energy, vol. 42, no. 19, pp. $13554-13567,2017$.

[20] L. Arriaga, W. Martinez, U. Cano, and H. Blud, "Direct coupling of a solar-hydrogen system in mexico," International Journal of Hydrogen Energy, vol. 32, no. 13, pp. 2247-2252, 2007.

[21] E. Cetin, A. Yilanci, Y. Oner, M. Colak, I. Kasikci, and H. K. Ozturk, "Electrical analysis of a hybrid photovoltaic-hydrogen/fuel cell energy system in denizli, turkey," Energy and Buildings, vol. 41, no. 9, pp. 975-981, 2009.

[22] M. Cilogulları, M. Erden, M. Karakilcik, and I. Dincer, "Investigation of hydrogen production performance of a photovoltaic and thermal system,"
International Journal of Hydrogen Energy, vol. 42, no. 4, pp. 25472552, 2017.

[23] B. Guinot, B. Champel, F. Montignac, E. Lemaire, D. Vannucci, S. Sailler, and Y. Bultel, "Techno-economic study of a pv-hydrogenbattery hybrid system for off-grid power supply: Impact of performances' ageing on optimal system sizing and competitiveness," International Journal of Hydrogen Energy, vol. 40, no. 1, pp. 623-632, 2015.

[24] A. Yilanci, I. Dincer, and H. K. Ozturk, "A review on solar-hydrogen/fuel cell hybrid energy systems for stationary applications," Progress in Energy and Combustion Science, vol. 35, no. 3, pp. 231-244, 2009.

[25] M. Eroglu, E. Dursun, S. Sevencan, J. Song, S. Yazici, and O. Kilic, "A mobile renewable house using pv/wind/fuel cell hybrid power system," International Journal of Hydrogen Energy, vol. 36, no. 13, pp. 79857992, 2011.

[26] E. Eriksson and E. Gray, "Optimization and integration of hybrid renewable energy hydrogen fuel cell energy systems - a critical review," Applied Energy, vol. 202, pp. 348-364, 2017.

[27] B. Escobar, J. Hernández, R. Barbosa, and Y. Verde-Gómez, "Analytical model as a tool for the sizing of a hydrogen production system based on renewable energy: The mexican caribbean as a case of study," International Journal of Hydrogen Energy, vol. 38, no. 28, pp. 12562 $12569,2013$.

[28] S. Pfenninger, A. Hawkes, and J. Keirstead, "Energy systems modeling for twenty-first century energy challenges," Renewable and Sustainable Energy Reviews, vol. 33, pp. 74-86, 2014.

[29] L. Schmeling, P. Schönfeldt, P. Klement, S. Wehkamp, B. Hanke, and C. Agert, "Development of a Decision-Making Framework for Distributed Energy Systems in a German District," Energies, vol. 13, no. 3, p. 552, 2020.

[30] E. Løken, "Use of multicriteria decision analysis methods for energy planning problems," vol. 11, pp. 1584-1595, 2005.

[31] D. Buoro, M. Casisi, A. de Nardi, P. Pinamonti, and M. Reini, "Multicriteria optimization of a distributed energy supply system for an industrial area," Energy, vol. 58, pp. 128-137, 2013.

[32] M. Di Somma, B. Yan, N. Bianco, G. Graditi, P. B. Luh, L. Mongibello, and V. Naso, "Operation optimization of a distributed energy system considering energy costs and exergy efficiency," Energy Conversion and Management, vol. 103, pp. 739-751, 2015.

[33] M. Carvalho, M. A. Lozano, and L. M. Serra, "Multicriteria synthesis of trigeneration systems considering economic and environmental aspects," Applied Energy, vol. 91, no. 1, pp. 245-254, 2012.

[34] P. N. Ngatchou, A. Zarei, W. L. J. Fox, and M. A. El-Sharkawi, "Pareto Multiobjective Optimization," in Modern Heuristic Optimization Techniques, K. Y. Lee and M. A. El-Sharkawi, Eds. Hoboken, NJ, USA: John Wiley \& Sons, Inc, 2008, pp. 189-207.

[35] M. Orner, Nutzungsorientierte Auslegung des Antriebsstrangs und der Reichweite von Elektrofahrzeugen. Wiesbaden: Springer Fachmedien, 2018.

[36] Verein Deutscher Ingenieure, "VDI 2067 - Economic efficiency of building installations: Fundamentals and economic calculation," Berlin, September 2012.

[37] R. A. Brealey, S. C. Myers, and F. Allen, Principles of corporate finance, ser. The McGraw-Hill Irwin series in finance, insurance, and real estate. Maidenhead: McGraw-Hill Education, 2014.

[38] K. Heuck, K.-D. Dettmann, and D. Schulz, Elektrische Energieversorgung: Erzeugung, Übertragung und Verteilung elektrischer Energie für Studium und Praxis. Wiesbaden: Springer Vieweg, 2013.

[39] F. Rubik, R. Müller, R. Harnisch, B. Holzhauer, M. Schipperges, and S. Dr. Geiger, "Umweltbewusstsein in Deutschland 2018: Ergebnisse einer repräsentativen Bevölkerungsumfrage,” Berlin, 2019. [Online]. Available: https://www.umweltbundesamt.de/sites/default/files/medien/ 1410/publikationen/ubs2018_-_m_3.3_basisdatenbroschuere_barrierefre i-02_cps_bf.pdf

[40] G. P. Peters, "Carbon footprints and embodied carbon at multiple scales," Current Opinion in Environmental Sustainability, vol. 2, no. 4, pp. 245250, 2010.

[41] S. Wehkamp, L. Schmeling, L. Vorspel, F. Roelcke, and K.-L. Windmeier, "District Energy Systems: Challenges and New Tools for Planning and Evaluation," Energies, vol. 13, no. 11, p. 2967, 2020.

[42] Bundesamt für Wirtschaft und Ausfuhrkontrolle, "Merkblatt zu den CO2-Faktoren: Energieeffizienz in der Wirtschaft - Zuschuss und Kredit," Eschborn, 2019. [Online]. Available: https://www.bafa.de/Shar edDocs/Downloads/DE/Energie/eew_merkblatt_co2.html 
[43] B. Tranberg, O. Corradi, B. Lajoie, T. Gibon, I. Staffell, and G. B. Andresen, "Real-time carbon accounting method for the european electricity markets," Energy Strategy Reviews, vol. 26, p. 100367, 2019.

[44] K.-L. Windmeier, "Länderspezifische berechnung der spezifischen c02emissionen des stromverbrauchs im europäischen verbundnetz," Internship Report, University of Bremen and KEHAG Energiehandel, 2019.

[45] M. Gröger, D. Berking, A. Ludwig, and T. Bruckner, "Kraft-WärmeKopplung und Solarthermie:: Konkurrenzeffekte beim integrierten Einsatz: Presentation," Wien, 2013. [Online]. Available: https://docpla yer.org/2900333-Kraft-waerme-kopplung-und-solarthermie.html

[46] S. von Roon and M. Huck, "Merit Order des Kraftwerkparks," Munich, 2010. [Online]. Available: https://www.ffe.de/download/wisse n/20100607_Merit_Order.pdf

[47] E.-M. Klotz, M. Koepp, F. Peter, N. Thamling, M. Wünsch, I. Ziegenhagen, B. Dr. Eikmeier, M. Fette, K. Janßen, E. Prof Dr. Jochem, F. Dr. Reitze, M. Schön, F. Dr. Toro, and M. Gailfuß, "Potenzial- und Kosten-Nutzen-Analyse zu den Einsatzmöglichkeiten von Kraft-Wärme-Kopplung (Umsetzung der EU-Energieeffizienzrichtlinie) sowie Evaluierung des KWKG im Jahr 2014," Berlin, 2014. [Online]. Available: https://www.prognos.com/upl oads/tx_atwpubdb/141001_Prognos_BMWi_Bericht_KWK.pdf

[48] T. M. Kneiske and M. Braun, "Flexibility potentials of a combined use of heat storages and batteries in pv-chp hybrid systems," Energy Procedia, vol. 135, pp. 482-495, 2017.

[49] K. K. Shah, A. S. Mundada, and J. M. Pearce, "Performance of u.s. hybrid distributed energy systems: Solar photovoltaic, battery and combined heat and power," Energy Conversion and Management, vol. 105 , pp. 71-80, 2015 .

[50] R. Viral and D. K. Khatod, "Optimal planning of distributed generation systems in distribution system: A review," Renewable and Sustainable Energy Reviews, vol. 16, no. 7, pp. 5146-5165, 2012.

[51] P. Prakash and D. K. Khatod, "Optimal sizing and siting techniques for distributed generation in distribution systems: A review," Renewable and Sustainable Energy Reviews, vol. 57, pp. 111-130, 2016.

[52] D. Connolly, H. Lund, B. V. Mathiesen, and M. Leahy, "A review of computer tools for analysing the integration of renewable energy into various energy systems," Applied Energy, vol. 87, no. 4, pp. 1059-1082, 2010 .

[53] S. Sinha and S. S. Chandel, "Review of software tools for hybrid renewable energy systems," Renewable and Sustainable Energy Reviews, vol. 32, pp. 192-205, 2014.

[54] L. Schmeling, P. Klement, T. Erfurth, J. Kästner, B. Hanke, K. von Maydell, and C. Agert, "Review of different software solutions for the holistic simulation of distributed hybrid energy systems for the commercial energy supply," in 33rd European Photovoltaic Solar Energy Conference and Exhibition, A. Smets, N. Taylor, and P. Helm, Eds. 2017, pp. 1994-1998.

[55] U. Krien, P. Schönfeldt, J. Launer, S. Hilpert, C. Kaldemeyer, and G. Pleßmann, "oemof.solph-a model generator for linear and mixedinteger linear optimisation of energy systems," Software Impacts, vol. 6 , p. $100028,2020$.

[56] S. Hilpert, "Effects of decentral heat pump operation on electricity storage requirements in germany," Energies, vol. 13, no. 11, p. 2878, 2020.

[57] C. Boysen, C. Kaldemeyer, S. Hilpert, and I. Tuschy, "Integration of flow temperatures in unit commitment models of future district heating systems," Energies, vol. 12, no. 6, p. 1061, 2019.

[58] W. E. Hart, C. Laird, J.-P. Watson, and D. L. Woodruff, Pyomo Optimization Modeling in Python, ser. Springer Optimization and Its Applications. Boston, MA: Springer US, 2012, vol. 67.

[59] S. Hilpert, C. Kaldemeyer, U. Krien, S. Günther, C. Wingenbach, and G. Plessmann, "The Open Energy Modelling Framework (oemof) - A new approach to facilitate open science in energy system modelling," Energy Strategy Reviews, vol. 22, pp. 16-25, 2018.

[60] J. Töpler and J. Lehmann, Wasserstoff und Brennstoffzelle. Berlin, Heidelberg: Springer, 2017.

[61] Eike Mollenhauer, Andreas Christidis, and George Tsatsaronis, "Evaluation of an energy- and exergy-based generic modeling approach of combined heat and power plants," International Journal of Energy and Environmental Engineering, vol. 7, no. 2, pp. 167-176, 2016.

[62] F. Salgado and P. Pedrero, "Short-term operation planning on cogeneration systems: A survey," Electric Power Systems Research, vol. 78, no. 5, pp. 835-848, 2008 .
[63] P. Kurzweil and O. K. Dietlmeier, Elektrochemische Speicher. Wiesbaden: Springer Fachmedien, 2018.

[64] W. Gleißner, Grundlagen des Risikomanagements im Unternehmen: Controlling, Unternehmensstrategie und wertorientiertes Management, ser. Management competence. Munich: Vahlen, 2011.

[65] G. Abdollahi and H. Sayyaadi, "Application of the multi-objective optimization and risk analysis for the sizing of a residential small-scale cchp system," Energy and Buildings, vol. 60, pp. 330-344, 2013.

[66] U. Arnold and Ö. Yildiz, "Economic risk analysis of decentralized renewable energy infrastructures - a monte carlo simulation approach," Renewable energy, vol. 77, pp. 227-239, 2015.

[67] M. Ristimäki, A. Säynäjoki, J. Heinonen, and S. Junnila, "Combining life cycle costing and life cycle assessment for an analysis of a new residential district energy system design," Energy, vol. 63, pp. 168-179, 2013.

[68] L. Urbanucci and D. Testi, "Optimal integrated sizing and operation of a chp system with monte carlo risk analysis for long-term uncertainty in energy demands," Energy Conversion and Management, vol. 157, pp. $307-316,2018$ 